REVIEW

\title{
Effectiveness of female controlled barrier methods in preventing sexually transmitted infections and HIV: current evidence and future research directions
}

\author{
A M Minnis, N S Padian
}

Sex Transm Infect 2005;81:193-200. doi: 10.1136/sti.2003.007153

See end of article for authors' affiliations authors' affiliations

Correspondence to: Alexandra M Minnis, PhD, $\mathrm{MPH}$, Department of Obstetrics, Gynecology and Reproductive Sciences, University of California San Francisco, 74 New Montgomery, Suite 600, San Francisco, CA 94105, USA; aminnis@psg.ucsf.edu

Accepted for publication 9 September 2004 effectiveness of female controlled physical and chemical barrier Objectives: To evaluate evidence for the effectiveness of female controlled physical and chemical barrier
methods in preventing STI/HIV transmission, to examine recent reviews on microbicide development, and to highlight promising research directions. To discuss challenges in conducting effectiveness research and in translating results to public health intervention.

Methods: Systematic review of articles that examined the disease prevention effectiveness of at least one female controlled barrier method. Review of conference abstracts that presented clinical and preclinical microbicide data.

Results: Randomised controlled trials provide evidence that female condoms confer as much protection from STIs as male condoms. Observational studies suggest that the diaphragm protects against STI pathogens. Several microbicide effectiveness studies are under way and new directions, such as adaptation of therapeutic agents as preventive products, are being examined. Substantial attention is now given to product formulation and novel delivery strategies. Combining microbicide products with different mechanisms of action as well as combining chemical and physical barriers will be necessary to maximise prevention effectiveness.

Conclusions: Increased investment in the development and identification of female controlled barrier methods offers promise that additional products will be available in the years ahead. Generalising trial results to a community setting, promoting products that may be less effective than male condoms, and bringing an effective product to scale introduce public health challenges that warrant attention. The need for female controlled barrier methods that provide women with the opportunity to take an active role in reducing their STI/HIV risk are urgently needed and constitute an essential tool to prevent continued spread of these infections.
W ith a persistent epidemic of heterosexually acquired HIV and an effective vaccine still years away, the need for female controlled physical and chemical barrier methods to prevent sexually transmitted diseases, including HIV, remains paramount. ${ }^{12}$ Women currently account for one half of the estimated 40 million HIV infections worldwide, and young women aged 15-24 years are 2.5 times more likely to be infected than young men. Most infections in women occur within a steady relationship or marriage. ${ }^{3}$ Though male condoms are known to be highly effective in preventing sexually transmitted HIV and many STIs, gender power imbalances in sexual partnerships require prevention methods that can be used by women without requiring partner negotiation during sexual intercourse. Furthermore, methods that may be used without detection during sex are critical.

The first modern female controlled physical barrier methods-cervical caps and diaphragms-were developed in Europe, and later, the United States, in the early 19th century ${ }^{4}$; only the sponge and female condom have been developed and approved for use since this time. These methods have been evaluated primarily for their contraceptive efficacy; however, several investigations of their disease prevention effectiveness have been conducted or are ongoing. Microbicides, antimicrobial products that are applied topically to the genital epithelium to offer a chemical barrier to STIs and HIV, constitute a substantial, and promising, focus of prevention method development. Currently, over 60 microbicides are in various phases of development, with six currently in or planned for advanced safety and effectiveness field trials.
This review evaluates the evidence for effectiveness of female controlled physical and chemical barriers in preventing STI and HIV transmission. Because no effectiveness results are available, we highlight the most promising products currently in clinical trials, and discuss directions for future research. In addition, we present controversies and challenges in designing and conducting effectiveness research and discuss issues relevant to translating effectiveness results to public health intervention. Though method acceptability directly influences use and, thereby, effectiveness assessments, we do not examine acceptability and use in this review. ${ }^{5}$

\section{METHODS}

\section{Selection of studies for review}

We identified studies for review through the National Library of Medicine's Medline database accessed through PubMed, and through POPLINE, an online database of published and unpublished references maintained by the Population Information Program at the Johns Hopkins School of Public Health. We searched the National Library of Medicine's AIDSLINE database for conference abstracts and the reference lists in articles selected for review. We conducted searches using the following search terms, individually and

Abbreviations: HEC, hydroxyethylcellulose; HSV, herpes simplex virus; IUD, intrauterine device; N-9, nonoxynol-9; PEP, post-exposure prophylaxis; PID, pelvic inflammatory disease; PSA, prostate specific antigen; SIV, simian immunodeficiency virus; STI, sexually transmitted infections 
in combination: HIV; sexually transmitted diseases; contraceptive devices, female; disease prevention; female controlled methods; female condom; cervical cap; diaphragm; microbicides; topical microbicide; efficacy; and effectiveness. We reviewed all articles published in peer reviewed journals that examined the disease prevention effectiveness of at least one female controlled barrier method, regardless of the design and study population. In addition, we examined review papers on this topic and relevant conference abstracts. To supplement the microbicide assessment, we reviewed materials included on the Alliance for Microbicide Development website and the abstracts and presentations from the Microbicides 2002 and 2004 conferences.

\section{PHYSICAL BARRIER METHODS}

\section{Female condoms}

Laboratory and epidemiological studies have demonstrated that polyurethane female condoms offer protection against STI pathogens, and that protection probably matches that conferred by male condoms. ${ }^{6}$

Since its introduction, numerous investigations have examined female condom acceptability and use; however, only four published studies have assessed directly the effectiveness of female condoms in preventing STIs. ${ }^{7}$ Soper et al assessed trichomoniasis re-infection and found that none of the women who used the female condom during each act of sexual intercourse were re-infected 45 days after treatment. ${ }^{8}$ Though this finding offers compelling evidence of a protective effect of the female condom, the sample was small and the period of follow up was short. Women were given female condoms to use only if they thought they could be compliant users. A dose-response relation of the female condom's effect on trichomoniasis re-infection among the inconsistent users substantiates the conclusion that the female condom offered a protective effect.

Three studies used a randomised controlled design to evaluate female condom effectiveness and they suggest that the availability and use of female condoms offer at least as much protection from STIs as male condoms alone (see table 1). Fontanet et al randomised sex establishments in Thailand to a male condom only arm or to a male and female condom arm. ${ }^{9}$ A statistically significant reduction was demonstrated in only one of the four cities but, at all sites, female condoms were at least as effective as male condoms. French et al developed a condom intervention among female clients at public STD clinics in Philadelphia and randomised women either to a female or male condom arm. ${ }^{10}$ They detected no statistically significant difference in STI prevalence between arms, though the direction of the odds ratio suggested that female condom availability might confer greater STI protection. ${ }^{10}$ None the less, several limitations should be noted, including assessment of incident STIs through medical record abstraction (50\% of women did not have prospective test results) and availability of condom use data for a subsample of females only.

A community randomised trial conducted by Feldblum et al in six matched pairs of Kenyan plantations was designed to examine the additional effect on STI prevalence of the availability of female condoms as part of a prevention programme that included male condom distribution, individual counselling, group meetings, and video and folk presentations. ${ }^{11}$ Over 1 year, STI prevalence did not vary between the two arms. Qualitative interviews indicated that the female condom was not accepted or promoted consistently by those clinic based providers who participated in both delivery of the intervention and data collection, which probably contributed to an inability to determine an additional effect of the female condom. ${ }^{11}$

\section{Female condom re-use}

Though the female condom is approved as a single use product, reports of re-use of the device have been noted..$^{12}$ To examine the safety of re-use, the World Health Organization convened a consultation in January 2002. ${ }^{13}$ They concluded that, though use of a new female condom during each act of intercourse should be recommended, female condoms can be re-used, with careful attention to a disinfection ( $1: 20$ dilution of household bleach), washing, drying and re-lubrication procedure. Research on the integrity of female condom re-use to date primarily has been laboratory based ${ }^{14-16}$ and suggests that the integrity of the female condom is maintained for at least five uses (if the disinfection recommendations are followed). ${ }^{16}$ Additional research that examines the STI/HIV prevention effectiveness of female condom re-use through population based studies is needed to inform policy recommendations.

\section{Cervical barriers}

The cervix constitutes a primary site of entry for STIs and HIV. ${ }^{17}$ Simian immunodeficiency virus (SIV)/macaque models $^{18}$ and a study of HIV acquisition in women with hysterectomies $^{19}$ demonstrate that HIV can be acquired vaginally; expression of CD4 cells and CCR5 chemokine receptors is higher in the cervix than the vagina. ${ }^{20}$ The cervical columnar epithelium is thinner than vaginal epithelium, making it more fragile, particularly among oral contraceptive users and during adolescence when ectopy is common. ${ }^{21}$ Thus, barriers that protect the cervix are

Table 1 Epidemiological evidence for the STI prevention effectiveness of female condoms

\begin{tabular}{|c|c|c|c|c|c|c|}
\hline Author & Year & Study population & No & Design & Outcomes & Key findings \\
\hline Soper et $a l^{8}$ & 1993 & $\begin{array}{l}\text { Gynaecology clinic patients with } \\
\text { trichomoniasis (United States) }\end{array}$ & 104 & $\begin{array}{l}\text { Prospective } \\
\text { cohort }\end{array}$ & Trichomoniasis & $\begin{array}{l}\text { No compliant female condom users re- } \\
\text { infected } v 14 \% \text { of women not given female } \\
\text { condoms and } 14.7 \% \text { of non-compliant } \\
\text { users }(p=0.08) \text {. }\end{array}$ \\
\hline Fontanet et $a l^{9}$ & 1998 & $\begin{array}{l}\text { Sex workers in commercial sex } \\
\text { establishments (Thailand) }\end{array}$ & 548 & $\begin{array}{l}\text { Randomised } \\
\text { controlled trial }\end{array}$ & $\begin{array}{l}\text { Chlamydia, gonorrhoea, } \\
\text { trichomoniasis, genital } \\
\text { ulcer disease }\end{array}$ & $\begin{array}{l}\text { Any STI: RR }=0.76(95 \% \mathrm{Cl}: 0.50 \text { to } 1.16) \\
\text { Reduction in STIs in } 1 \text { of } 4 \text { sites: } R R=0.47 \\
(95 \% \mathrm{Cl}: 0.25 \text { to } 0.91)\end{array}$ \\
\hline Feldblum et $a l^{11}$ & 2001 & $\begin{array}{l}\text { Women in six matched community } \\
\text { pairs (Kenya) }\end{array}$ & 1752 & $\begin{array}{l}\text { Community } \\
\text { randomised } \\
\text { controlled trial }\end{array}$ & $\begin{array}{l}\text { Chlamydia, gonorrhoea, } \\
\text { trichomoniasis }\end{array}$ & Any STI: OR= $1.1(95 \% \mathrm{Cl}: 0.8$ to 1.6$)$ \\
\hline French et $a l^{10}$ & 2003 & $\begin{array}{l}\text { Women seen at STD clinic (United } \\
\text { States) }\end{array}$ & 1442 & $\begin{array}{l}\text { Randomised } \\
\text { controlled trial }\end{array}$ & $\begin{array}{l}\text { Chlamydia, gonorrhoea, } \\
\text { trichomoniasis, syphilis }\end{array}$ & $\begin{array}{l}\text { Any STI, comparing female + male } \\
\text { condoms to male condom alone: } \\
\mathrm{RR}=0.79(95 \% \mathrm{Cl}: 0.59 \text { to } 1.06)\end{array}$ \\
\hline
\end{tabular}




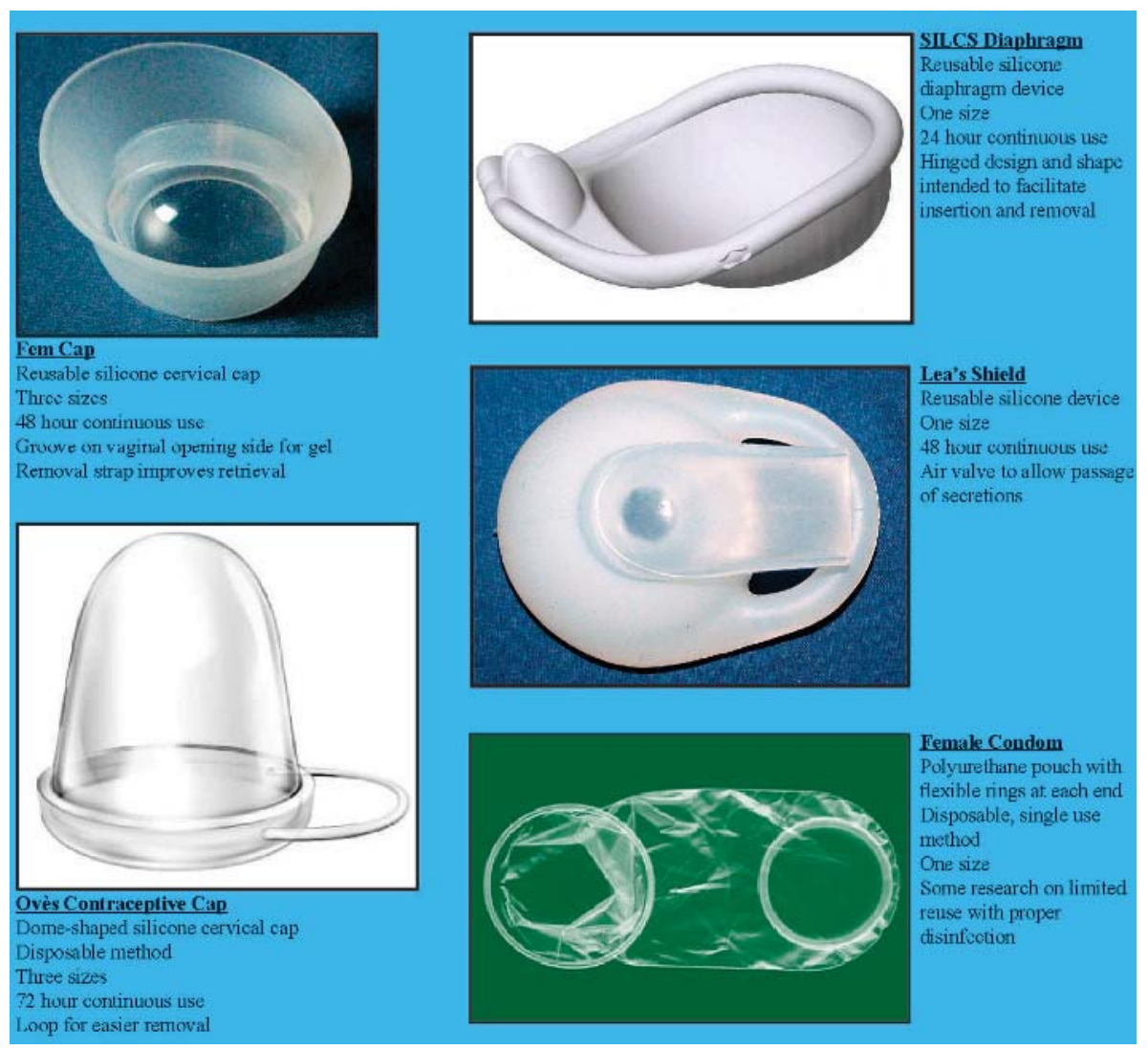

Figure 1 Samples of recently developed physical barrier devices: FemCap, Ovès Contraceptive Cap, SILCS diaphragm (under development), Lea's Shield, and female condom.

considered strong HIV prevention candidates. To date, all studies of diaphragm STI prevention effectiveness have been observational, and several are limited by their consideration of multiple barrier methods simultaneously. Currently, several diaphragm effectiveness randomised controlled trials are under way, including a study in Zimbabwe and South Africa of its HIV prevention effectiveness, and a study of its STI prevention effectiveness in Kenya. ${ }^{22}$ Cervical barrier method options have expanded from traditional latex diaphragms and cervical caps to include newer products made from silicone, such as the SILCS diaphragm, Lea's shield, Oves cervical cap, and FemCap (see fig 1). ${ }^{22}$

A recent review concluded that observational studies offer evidence that the diaphragm protects against STI pathogens, ${ }^{17}$ including gonorrhoea, ${ }^{23-26}$ pelvic inflammatory disease (PID), ${ }^{27}{ }^{28}$ tubal infertility, ${ }^{29}$ and cervical dysplasia. ${ }^{30-32}$ These data are summarised in table 2 and were described by Moench et al. ${ }^{17}$ There are several limitations to these data. Firstly, all the studies were either cross sectional or casecontrol in design and only considered "current method use" as their primary measure of method use. Secondly, diaphragm users may have a lower risk profile than nondiaphragm users. Indeed, in the study by Rosenburg et al, the prevalence of trichomoniasis, a non-cervical infection, was also lower among diaphragm users. ${ }^{25}$ Similarly, in the study by Wright et al, diaphragm users had a later age of first sexual intercourse than did pill or intrauterine device (IUD) users. ${ }^{32}$ Thirdly, the comparison groups varied and consisted of either women using non-barrier methods or not using contraception. These two groups may be distinct in their use of health care, in socioeconomic status, and in level of sexual activity or other behavioural practices that increase risk for STIs and would probably influence the observed measures of association. Finally, the simultaneous use of nonoxynol-9 (N-9) containing spermicidal gel with the diaphragm may have influenced the observed STI prevention effectiveness. The results from the ongoing diaphragm effectiveness trials will offer more definitive answers about the role of the diaphragm in HIV and STI prevention.

\section{CHEMICAL BARRIERS}

The ideal microbicide should prevent HIV and STIs without disrupting the vaginal or rectal mucosa, be effective for vaginal and rectal use for a wide range of STIs and HIV viral clades, offer contraceptive properties, retain local rather than systemic effects, and be affordable and resilient to transport and temperature. The approaches adopted for microbicide development are typically classified by their mechanism of action (table 3 ).

Several reviews of the state of microbicide development have been published recently. ${ }^{33-35}$ One, by Keller et al, focused specifically on preclinical development. They argued for testing microbicides in primary culture systems versus cell lines and used N-9 as an example of primary culture system research that pointed to adverse consequences not detected in cell lines. ${ }^{34}$ Harrison et al presented an update on microbicide development and highlighted several clinical research challenges. ${ }^{33}$ One relates to the difficulty of evaluating the potential efficacy of candidate products owing to the lack of available surrogate end points. Traditionally, phase II safety trials are designed to include evaluation of potential efficacy ("proof of concept"). But, in microbicide research, there are no accepted surrogate end points for HIV that can be assessed in these smaller studies. Other STIs have been used to demonstrate biological plausibility for microbicide products with general mechanisms of action, such as strengthening the natural vaginal defences (both in vitro and in phase II trials). In expanded phase I studies, examination of effects of candidate products on the genital tract immune microenvironment (for example, innate immunological factors, immune 
Table 2 Epidemiological evidence for STI prevention effectiveness of diaphragms*

\begin{tabular}{|c|c|c|c|c|c|c|}
\hline Authors & Year & Study population & No & Design & Outcome & $\begin{array}{l}\text { Key finding } \\
\text { Odds ratio }(95 \% \mathrm{Cl})\end{array}$ \\
\hline $\begin{array}{l}\text { Austin et } a l^{24} \\
\text { Bradbeer et } a l^{26} \\
\text { Kelaghan et } a l^{27} \\
\text { Wolner-Hanssen et } a l^{28} \\
\text { Cramer et } a l^{29} \\
\text { Becker et } a l^{30} \\
\text { Hildesheim et } a l^{31} \\
\text { Wright et } a l^{32}\end{array}$ & $\begin{array}{l}1984 \\
1987 \\
1982 \\
81990 \\
1987 \\
1994 \\
1990\end{array}$ & $\begin{array}{l}\text { STD clinic } \\
\text { Sex workers } \\
\text { Hospital } \\
\text { Health clinics } \\
\text { Hospital } \\
\text { Women's health clinics } \\
\text { Hospital with community } \\
\text { controls } \\
\text { Family planning clinics }\end{array}$ & $\begin{array}{r}1781 \\
100 \\
1481 \\
880 \\
4116 \\
538 \\
1267\end{array}$ & $\begin{array}{l}\text { Case-control } \\
\text { Cross sectional } \\
\text { Case-control } \\
\text { Case-control } \\
\text { Case-control } \\
\text { Case-control } \\
\text { Case-control } \\
\text { Prospective cohort } \\
\text { Case-control }\end{array}$ & $\begin{array}{l}\text { Chlamydia } \\
\text { Chlamydiał } \\
\text { Gonorrhoea } \\
\text { Gonorrhoea } \\
\text { Gonorrhoea } \\
\text { PID } \\
\text { PID } \\
\text { Tubal infertility } \\
\text { Cervical neoplasia } \\
\text { Cervical cancer } \\
\text { Cervical neoplasia }\end{array}$ & $\begin{array}{l}0 \dagger \\
0.25(0.05 \text { to } 1.36) \\
0.32(0.16 \text { to } 0.65) \\
0.45(0.15 \text { to } 0.3) \\
0.36(p<0.05) \\
0.4(0.2 \text { to } 0.7) \\
0.3(p=0.005) \\
0.5(0.3 \text { to } 0.7) \\
0.3(0.2 \text { to } 0.6) \S \\
<5 \text { years' use: } O R=0.9(0.6,1.3) \\
5+\text { years' use: } O R=0.8(0.4,1.6) \\
0.12 p<0.01 \\
0.23 p<0.05\end{array}$ \\
\hline \multicolumn{7}{|c|}{$\begin{array}{l}\text { *Includes observational studies that presented risk estimates adjusted for potential confounding factors. Five additional studies examined effects of physical barrie } \\
\text { method use on chlamydia, gonorrhoea and/or trichomoniasis; though, because they defined a combined barrier method measure for analysis (for example, mal } \\
\text { condom, diaphragm and nonoxynol-9 containing spermicides) these investigations, as published, are not informative in assessing the effectiveness of particula } \\
\text { methods (Park et al, } l_{1}^{74} \text { Quinn and } \mathrm{O}^{\prime} \text { Reilly }{ }_{1}^{75} \mathrm{McCormick} \text { et al }{ }_{1}^{76} \text { Berger et al, Keith et al }{ }^{78} \text { ). } \\
+0 / 77 \text { diaphragm users infected compared to } 20 \% \text { of non-users of contraception. } \\
\ddagger \text { Chlamydia assessed in only } 35 \text { of } 227 \text { diaphragm users. } \\
\text { §Odds ratio for use of diaphragm ever. Estimate for current use not significant: OR=0.5, } 95 \% \mathrm{Cl}: 0.2 \text { to } 1.9 \text {. }\end{array}$} \\
\hline
\end{tabular}

cell populations), alterations which influence acquisition of STIs, could facilitate early clinical screening of products. Anticipating product effectiveness from adverse safety outcomes (limited local toxicity, evidence of damage to vaginal and cervical epithelium) remains challenging, as the degree to which microbicide toxicity alters HIV/STI susceptibility may not be measured well by current techniques, and the clinical significance of abnormal findings is sometimes difficult to establish. A need exists for more sensitive indicators of microbicide induced inflammatory responses that could increase HIV/STI susceptibility and infectiousness.

Though the majority of microbicide products are currently in preclinical development, ${ }^{36} 18$ products are being evaluated now in clinical research studies, most in small phase I safety and acceptability trials. Furthest along in the development pipeline, either because they are already in phase II/IIb (expanded safety) or phase III (effectiveness) trials, or are anticipated to enter field trials in 2004 are Carraguard, Pro2000, Buffergel, C31G/Savvy, Dextrin-2-Sulfate/Emmelle and Cellulose sulfate. Most of these products function by disrupting the viral membrane or by blocking viral entry into and binding with the target cells.

Recently, products that target specific stages of the viral life cycle have been developed and adapted from therapeutics.
For example, reverse transcriptase inhibitor antiviral agents used topically may, after local infection occurs, prevent viral replication and systemic infection. A phase I study of vaginal application of tenofovir gel demonstrated that it was well tolerated among sexually active women, and pharmacokinetic data indicated minimal product absorption (the highest concentrations detected were only $10 \%$ of the lowest concentration given orally to HIV infected individuals). ${ }^{37}$ Resistance may result from repeated use over longer periods and, although characterisation of resistance is recommended as part of preclinical evaluation, ${ }^{38}$ this should be monitored in clinical studies. Preclinical research has suggested that combining tenofovir with a non-nucleoside reverse transcriptase inhibitor, such as UC-781, may offer synergistic effects. ${ }^{39}$ Furthermore, UC-781 demonstrates a strong memory effect and was found to inhibit HIV replication in cervical tissue explants 6 days following drug treatment. ${ }^{40}$ The suggestion of potential products that do not need to be applied immediately before intercourse represents an important development that can lead to enhanced flexibility regarding timing of use.

\section{FUTURE DIRECTIONS FOR MICROBICIDE RESEARCH}

Several challenges and directions for microbicide development are highlighted consistently: (1) product formulation

Table 3 Primary mechanisms of action for microbicide products with selected examples

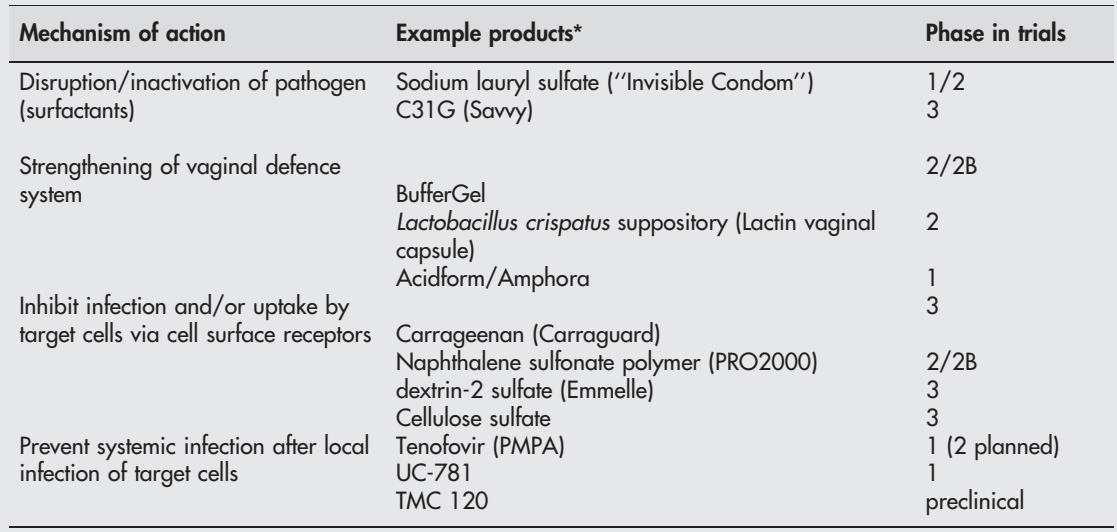

*See Alliance for Microbicide Development website for complete list of candidate microbicides and further description of potential mechanisms of action (www.microbicide.org) 


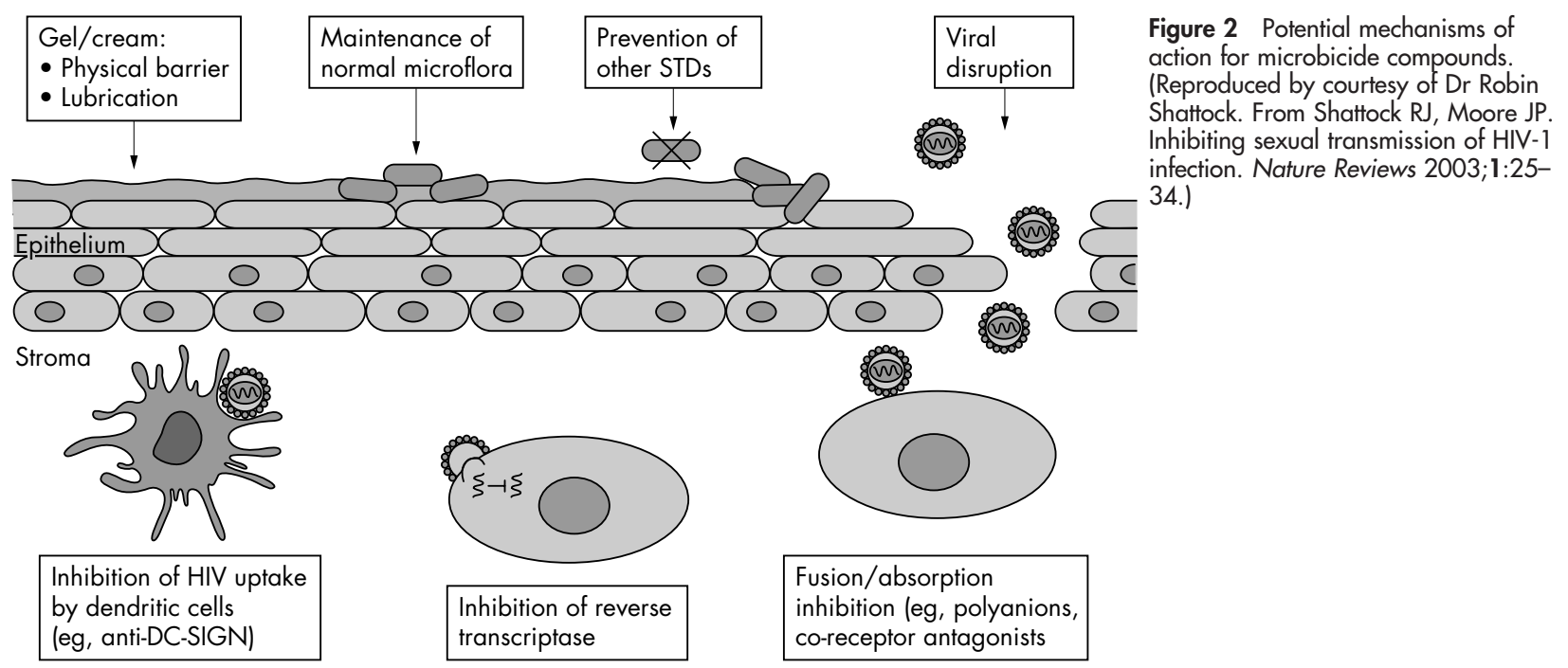

and delivery; (2) development of products either for rectal use, specifically, or that are suitable for both the genital and gastrointestinal tracts; and (3) the development of combination products-both to inactivate the HIV virus using several approaches and to inhibit several STI pathogens simultaneously.

Critical issues related to product formulation and delivery include product coverage of the vaginal area, application method, dosage, volume, and concerns regarding systemic effects of a product that is absorbed and/or ascends the reproductive tract. Formulation and volume greatly affect product diffusion. Barnhard et al have developed strategies for examining product diffusion using magnetic resonance imaging. ${ }^{41}$ Product acceptability, frequency of product use, and frequency of coital activity are linked closely with each of these issues. One particular challenge with vaginal delivery of microbicide products has been the need to provide a sufficiently high dose that offers protection for multiple hours and/or sexual acts. Malcolm et al have adapted the contraceptive intravaginal ring as a potential microbicide delivery device (using N-9 and, more recently, dextran sulfate, $^{42}$ as models), which, through a more controlled delivery, lowers the dose and volume of product required to achieve therapeutic effectiveness. ${ }^{43}$ A controlled release delivery system could not only reduce adverse effects on vaginal epithelium and, potentially, systemic effects, but also improve user acceptability. Nucleotide reverse transcriptase inhibitors may be most compatible with rings because of their molecular weight. ${ }^{44}$ Devices capable of releasing larger molecular weight products have been developed. For example, in a mouse model, vaginal discs that released antibody to HSV-2, demonstrated protection from HSV-2 infection. ${ }^{45}$ Intravaginal devices could be designed as compartmentalised to accommodate multiple microbicide products. ${ }^{44}$ Other innovative microbicide delivery vehicles pursued currently are genetic modification of native vaginal lactobacilli to deliver anti-HIV products ${ }^{46}$ and penile wipes. ${ }^{47}$

As recent studies have suggested that, in some geographic areas, $20-40 \%$ of heterosexual women may engage in anal intercourse, development of a microbicide for rectal use has a direct HIV prevention role for women ${ }^{48}{ }^{49}$ (in addition to its role for men who have sex with men). Differences in the anatomy, histopathology, and microbiology of the genital and rectal sites make development of a product that could be used interchangeably at either one difficult. The specific mechanism of HIV transmission during anal intercourse remains to be elucidated and it is unclear whether a product would need to protect the rectal cavity or would have to provide activity in more proximal sites such as the sigmoid colon. The latter scenario presents significant formulation issues in ensuring uniform delivery of product to the vulnerable mucosa. Cyanovirin-N has recently been shown to prevent infection in the macaque/SHIV model of rectal infection. ${ }^{50}$ The techniques used for evaluating safety of vaginal microbicides may be insufficient for the rectal mucosa where subtle immunological toxicity may cause significant increases in mucosal transmission in the absence of overt mucosal inflammation. To date, the one phase 1 rectal microbicide study that has been conducted evaluated escalating doses of an N-9 product. ${ }^{51}$ Although the product was reasonably well tolerated, N-9 was subsequently deemed unsuitable as a microbicide. ${ }^{52}$

There is growing consensus that developing a microbicide that offers a high level of protection from HIV and other STI pathogens will require a combination of products that act through different mechanisms of action and compounds (see fig 2). ${ }^{53}$ This combination may be two microbicide products or the combination of a cervical barrier and a microbicide. Combination microbicides might block transmission at multiple points in the infection process (for example, disrupt the viral envelope and prevent replication of infected cells using antiviral therapy); act at different tissue sites (for example, epithelium, lymph node); and provide protection against multiple infections ${ }^{35}{ }^{53}$ that are known to increase risk for HIV through their disruption of protective epithelial surfaces. Furthermore, a combination microbicide product may minimise resistance that may develop towards products designed to initiate specific cellular activity and expand product effectiveness across multiple viral clades. Though physical and chemical barriers primarily have been developed independently of each other, the combination of cervical barriers and microbicides offers a compelling approach to STI and HIV prevention. The BufferGel cap, for example, is being developed as a cervical barrier for delivery of BufferGel microbicide. An expanded phase I safety study of Instead Softcup (a disposable diaphragm) and AcidForm gel is planned for South Africa (M Callahan, personal communication, 23 August 2004).

\section{METHODOLOGICAL CONTROVERSIES IN STUDY DESIGN}

The most rigorous and efficient design for phase III effectiveness trials of microbicide products and physical 
barrier methods remains controversial. Owing to ethical obligations to provide study participants with the most effective prevention methods available-currently, male condoms and counselling in their use-only the marginal effectiveness of providing an additional product can be assessed in an effectiveness trial. ${ }^{54}$ This, clearly, requires a larger study, which adds complexity and expense.

The US Food and Drug Administration has announced that initial evaluations of microbicide products should include two control arms: a placebo and a condom only arm. ${ }^{55}$ Given the added expense and time required to recruit, enrol and follow additional participants for regular behavioural and biological assessments, the utility of including two control arms has been debated by Stein et al and by Padian. ${ }^{56} 57$ The placebo product (plus condom) arm retains the double blinded feature of the randomised controlled trial, which permits direct assessment of the experimental product, unbiased by differences in behaviour and study retention. Furthermore, it provides opportunity for assessment of whether the active product offers disease prevention properties above and beyond lubrication effects. Developing and/or identifying a placebo product that lacks antimicrobial activity is challenging and, as demonstrated in the COL-1492 trial of nonoynol-9, ${ }^{58}$ a placebo product may also offer protective properties that minimise the ability to detect an effect of the active product being evaluated. In addition, placebos can modify the immune activation status of the reproductive tract, and evidence suggests that some placebos planned for use may have HIV activity that offers unintended protection. ${ }^{59}$ Thus, a condom only arm allows assessment of the protective effect of the placebo, which may be essential. Much progress has been made in developing an inert placebo product, with HEC (hydroxyethylcellulose) now available for effectiveness trials. ${ }^{60}$

In light of the urgency with which an effective microbicide product is needed, conducting efficient trials that maintain the highest scientific rigor remains important. Two strategies that could reduce the size, time, and cost of the phase III effectiveness trials are use of surrogate biological markers for HIV as the study end points and expanded use of phase IIb safety/limited effectiveness studies. ${ }^{61}{ }^{62}$ If an STI with higher incidence is used, such as herpes simplex virus 2 (HSV-2) or another immunological marker of STI and/or HIV susceptibility, the power to detect an effect would remain high with fewer participants followed for shorter periods of time. Through mathematical modelling of behavioural strategies for STI and HIV risk reduction, Pinkerton et al demonstrated that the appropriateness of a particular STI biomarker for HIV depends on how closely its infectivity reflects that of HIV. ${ }^{63} \mathrm{~A}$ smaller, phase IIb "screening" study, that includes an initial focus on safety and permits identification of a highly effective product (and, similarly, a rejection of a highly ineffective product), has been proposed as an alternative to moving directly from safety and acceptability investigations to a phase III effectiveness trial. This design is appealing as it offers a more efficient and cost effective strategy for screening out promising products that prove ineffective.

Alternative measures of effectiveness for STIs and HIV Examination of semen exposure, through tests such as prostate specific antigen (PSA), represents a novel measure of physical barrier method effectiveness employed in several recent studies. ${ }^{64-68}$ PSA tests detect relatively small amounts of semen, and, given the unknown infectious dose of the STI and HIV organisms, the consequences of these exposures to semen is unknown. Interpreting the public health significance of PSA levels requires additional research on what level of PSA exposure in semen is meaningful for disease transmission, and, given natural variation of PSA concentration in semen, what level of semen exposure indicates method failure.

\section{TRANSLATING EFFECTIVENESS RESULTS TO PUBLIC HEALTH INTERVENTION}

Translating results of effectiveness studies to public health intervention includes consideration of several issues. The first relates to generalising results from a trial to real use settings. In the context of a study trial, participants may use the study product(s) more frequently than individuals who are not in a trial, for reasons that include a sense of obligation to the research staff because they are being financially compensated for their participation, because they are receiving healthcare services through the trial, and because, by signing a consent form, they agreed to participate and use the study product(s) they are given. In addition, regular study visits, during which participants are asked questions about their method use frequency and are counselled on strategies for successful use of the products, may function as an intervention that promotes method use or changes in high risk behaviours. Furthermore, owing to trial eligibility criteria, participants may be healthier, more compliant, or otherwise different from those who ultimately use the product. In generalising study results, then, the population effect of the product may be overestimated because in a real use setting the consistency of product use may be lower than that achieved in the effectiveness trial.

\section{Condom migration}

Much attention has been given to the issue of condom migration-that is, movement away from condoms towards a less effective device or product. This may occur in studies if women in the product arm could have been consistent condom users but are not because the study product is now available to them. Examinations of this phenomenon, however, suggest that condom migration generally does not present a great public health dilemma. The female condom effectiveness study by Fontanet et al suggested that the availability of both male and female condoms did not influence the total proportion of protected acts, but may have reduced the proportion that were protected by male condoms. ${ }^{9}$ Foss et al presented a summary of the condom migration evidence from studies that offered condoms and spermicides and concluded that six of the nine studies found the expanded method options increased condom use and only in the remaining three did condom use decrease. ${ }^{69}$ They also included a model using data from Cotonou, Benin, to examine the hypothetical effects on HIV prevention of introducing a microbicide with 50\% HIV and STI prevention efficacy, assuming $10 \%$ condom migration. The model suggested that migration from condom use would only begin to increase risk among groups with initial condom use consistency greater than $70 \%$ and microbicide use lower than $50 \%$ for acts that were not protected by condoms. An examination of condom migration in a diaphragm acceptability study demonstrated that male condom use, with or without simultaneous use of a diaphragm, did not decrease over a 6 month period following introduction of the diaphragm. ${ }^{70}$ Thus, while some condom migration may occur, in general it does not appear to lead to a greater proportion of unprotected acts.

\section{Risk compensation}

Risk compensation, or an increase in risky behaviours as a result of an anticipated protective effect of an intervention, constitutes another potential public health issue. Indeed, this has been cited as a caution against the promotion of male condoms, particularly because of their varying levels of effectiveness across STI pathogens..$^{71}$ The hypothesis is that 
individuals accept a certain level of risk and that shifts in risk tolerance occur in the face of additional protection. For example, in the area of public health safety and injury prevention, the introduction of safety devices such as seat belts, helmets, and anti-lock brakes initiated concern that individuals would increase their driving speed and recklessness. ${ }^{72}$ A study of risk compensation among recipients of post-exposure prophylaxis (PEP) for potential sexual exposure to HIV found that individuals who received PEP did not increase their practice of risky sexual behaviours over the next year. ${ }^{73}$ The availability and promotion of microbicides and other cervical barriers may indeed prompt an increase in behavioural risks; however, no strong evidence exists that the promotion of male condoms, which may also prompt similar behavioural adjustments, has led to increased STI/HIV risk.

\section{Manufacturing and access}

Finally, ensuring the ability to manufacture a low cost product and/or device found to be effective in preventing HIV and STIs necessitates guidance from commercial manufacturers early on in product development. Consideration of strategies for a stepwise introduction that includes plans for which regions and population groups to target, how to educate providers and potential users, timeframe, ability to produce the product locally or regionally, and financing and licensing procedures are essential. Ideally, planning and advocacy on many of these issues will position the public health community to minimise delay between the identification of an effective product and its dissemination to communities at greatest risk for HIV infection.

\section{CONCLUSION}

With substantial public and private investment in the field of female controlled methods for HIV and STI prevention, we should expect tremendous advancement in the years ahead. It is anticipated that initial microbicides and cervical barriers may not be as effective as male condoms, but they will provide women with the opportunity to take an active role in reducing their risk without requiring partner negotiation during intercourse. Six microbicide products are currently being evaluated for effectiveness and numerous products are in the development pipeline. However, the objective of identifying effective female controlled methods should not obscure the ultimate goal of addressing vulnerability and gender inequities through gains in women's economic independence, educational attainment, and cultural shifts in gender based violence. Indeed, such changes may be required to facilitate use of female controlled methods by women who are most at risk for HIV infection, as these women may be most likely to believe their partner's cooperation is required, even for a method that is seemingly or, in fact, controlled by them. None the less, even if these long term and socially sustainable goals could be achieved, the mandate for female controlled barrier methods will remain an essential tool to prevent continued spread of the STI/HIV epidemics.

\section{ACKNOWLEDGEMENTS}

We thank Dr Ian McGowan at the David Geffen School of Medicine at the University of California Los Angeles for providing a summary on the status of rectal microbicide development for this manuscript. In addition, thanks are extended to Dr Ariane van der Straten for her review of an early version of the manuscript, to Joelle Brown for her contribution to review and synthesis of material presented at the Microbicides 2004 conference, and to Dr Kevin Whaley for his review and thoughtful suggestions for the manuscript.

\section{CONTRIBUTORS}

AM assumed primary responsibility for developing the manuscript, including defining its structure, reviewing the effectiveness literature and methodological challenges, and writing the text; NP provided input in all of these areas, particularly in outlining the scope of the review and in editing the text.

\section{Authors' affiliations}

A M Minnis, N S Padian, Department of Obstetrics, Gynecology and Reproductive Sciences, University of California San Francisco, CA, USA

\section{REFERENCES}

1 Stein ZA. HIV prevention: the need for methods women can use. Am J Public Health 1990;80:460-2.

2 Guinan M. HIV, heterosexual transmission, and women. JAMA 1992;268:520-1.

3 The Global Coalition on Women and AIDS. HIV prevention and protection efforts are failing women and girls. UNAIDS, 2004.

4 Tone A. Devices and desires: a history of contraception in America. New York: Hill and Wang, 2001.

5 Elias C, Coggins C. Acceptability research on female-controlled barrier methods to prevent heterosexual transmission of HIV: where have we been? Where are we going? J Women's Health Gend Based Med 2001; 10:163-73.

6 Drew WL, Blair M, Miner RC, et al. Evaluation of the virus permeability of a new condom for women. Sex Transm Dis 1990;17:110-12.

7 Future barrier methods. Contracept Rep 1997;8:9-13.

8 Soper DE, Shoupe D, Shangold GA, et al. Prevention of vaginal trichomoniasis by compliant use of the female condom. Sex Transm Dis 1993;20:137-9.

9 Fontanet A, Saba J, Chandelying V, et al. Protection against sexually transmitted diseases by granting sex workers in Thailand the choice of using the male or female condom: results from a randomized controlled trial. AIDS 1998; 12:1851-9.

10 French PP, Latka M, Gollub EL, et al. Use-effectiveness of the female versus male condom in preventing sexually transmitted disease in women. Sex Transm Dis 2003;30:433-9.

11 Feldblum PJ, Kuyoh MA, Bwayo JJ, et al. Female condom introduction and sexually transmitted infection prevalence: results of a community intervention trial in Kenya. AIDS 2001;15:1037-44.

12 Smith JB, Nkhama G, Trottier DA. Female condom reuse in Lusaka, Zambia: evidence from 12 cases. J Urban Health $2001 ; 78: 638-46$.

13 World Health Organization. The safety and feasibility of female condom reuse: report of a WHO consultation. Geneva: WHO, 2002:1-18.

14 Joanis C, Latka M, Glover $L H$, et al. Structural integrity of the female condom after a single use, washing, and disinfection. Contraception 2000;62:63-72.

15 Beksinska ME, Rees HV, Dickson-Tetteh KE, et al. Structural integrity of the female condom after multiple uses, washing, drying, and re-lubrication. Contraception $2001 ; 63: 33-6$.

16 Potter B, Gerofi J, Pope M, et al. Structural integrity of the polyurethane female condom after multiple cycles of disinfection, washing, drying and relubrication. Contraception 2003;67:65-72.

17 Moench TR, Chipato T, Padian NS. Preventing disease by protecting the cervix: the unexplored promise of internal vaginal barrier devices. AIDS 2001;15:1595-602.

18 Hu J, Gardner MB, Miller CJ. Simian immunodeficiency virus rapidly penetrates the cervicovaginal mucosa after intravaginal inoculation and infects intraepithelial dendritic cells. J Virol 2000;74:6087-95.

19 Farrar DJ, Cu Uvin S, Caliendo AM, et al. Detection of HIV-1 RNA in vaginal secretions of HIV-1-seropositive women who have undergone hysterectomy. AIDS 1997;11:1296-7.

20 Patterson B, Landay A, Andersson J, et al. Repertoire of chemokine receptor expression in the female genital tract: implications for human immunodeficiency virus transmission. Am J Pathol 1998;153:481-90.

21 Jacobson D, Peralta L, Graham N, et al. Histologic development of cervical ectopy: relationship to reproductive hormones. Sex Transm Dis 2000;27:252-8.

22 Ellertson C, Burns M. Re-examining the role of cervical barrier devices, Outlook. Seattle, WA: Program for Appropriate Technology in Health (PATH), 2003: 1-8.

23 Magder LS, Harrison HR, Ehret JM, et al. Factors related to genital Chlamydia trachomatis and its diagnosis by culture in a sexually transmitted disease clinic. Am J Epidemiol 1988;128:298-308.

24 Austin H, Louv WC, Alexander WJ. A case-control study of spermicides and gonorrhea. JAMA 1984;251:2822-4.

25 Rosenberg MJ, Davidson AJ, Chen JH, et al. Barrier contraceptives and sexually transmitted diseases in women: a comparison of female-dependent methods and condoms. Am J Public Health 1992;82:669-74.

26 Bradbeer C, Thin R, Tan T, et al. Prophylaxis against infection in Singaporean prostitutes. Genitourin Med 1988;64:52-3.

27 Kelaghan J, Rubin GL, Ory HW, et al. Barrier-method contraceptives and pelvic inflammatory disease. JAMA 1982;248:184-7

28 Wolner-Hanssen P, Eschenbach D, Paavonen J, et al. Decreased risk of symptomatic chlamydial pelvic inflammatory disease associated with oral contraceptive use. JAMA 1990;263:54-9.

29 Cramer D, Goldman M, Schiff I, et al. The relationship of tubal infertility to barrier method and oral contraceptive use. JAMA 1987;257:2446-50.

30 Becker TM, Wheeler CM, McGough NS, et al. Contraceptive and reproductive risks for cervical dysplasia in southwestern Hispanic and non-Hispanic white women. Int J Epidemiol 1994;23:913-22. 
31 Hildesheim A, Brinton LA, Mallin K, et al. Barrier and spermicidal contraceptive methods and risk of invasive cervical cancer. Epidemiology 1990; 1:266-72.

32 Wright N, Vessey M, Kenward B, et al. Neoplasia and dysplasia of the cervix uteri and contraception: a possible protective effect of the diaphragm. Br J Cancer 1978:38:273-9.

33 Harrison PF, Rosenberg Z, Bowcut J. Topical microbicides for disease prevention: status and challenges. Clin Infect Dis 2003;36:1290-4

34 Keller MJ, Klotman ME, Herold BC. Development of topical microbicides for prevention of human immunodeficiency virus and herpes simplex virus. Am J Reprod Immunol 2003;49:279-84.

35 Stone A. Microbicides: a new approach to preventing HIV and other sexually transmitted infections. Nat Rev Drug Discov 2002;1:977-85.

36 Garg S, Kandarapu R, Vermani K, et al. Development pharmaceutics of microbicide formulations. Part 1: Preformulation considerations and challenges. AIDS Patient Care and STD 2003;17:17-32.

37 Maslankowski L, Mayer K, El-Sadr W, et al. Vaginal tenofovir gel tolerability in HIV-uninfected women and abstinent HIV-infected women: HPTN 050. Microbicides 2004. London, 2004 (abstract number 02655)

38 Lard-Whiteford SL, Matecka D, O'Rear JJ, et al. Recommendations for the nonclinical development of topical microbicides for prevention of HIV transmission: an update. J Acquir Immune Defic Syndr 2004;36:541-52.

39 Schader S, Klasse P, Harman S, et al. PMPA-NNRTI combination studies demonstrate potent synergism against HIV-1 infection in vitro. Microbicides 2004. London, 2004: (abstract number, 02442)

40 Watts P, Wallace G, Mahmood N, et al. UC-781 blocks localised infection and cell 'dissemination pathways within human cervical tissue. Microbicides 2004. London, 2004 (abstract number 02639-- 3).

41 Barnhart K, Shera D, Pretorius E, et al. Optimal analysis of MRI data to quantitate the distribution of a vaginal product. Microbicides 2004. London, 2004 (abstract number 02420_2).

42 Malcolm K, Lowry D, Woolfson D. In vitro release of dextran sulfate from silicone intravaginal rings. Microbicides 2004. London, 2004: (abstract number 02665).

43 Malcolm K, Woolfson D, Russell J, et al. In vitro release of nonoxynol-9 from silicone matrix intravaginal rings. Journal of Controlled Release 2003:91:355-64

44 Malcolm K, Woolfson D. Intravaginal rings for the long-term controlled delivery of HIV microbicides. Microbicides 2004. London, 2004: (abstract number, FADS-02).

45 Sherwood JK, Zeitlin L, Whaley KJ, et al. Controlled release of antibodies for long-term topical passive immunoprotection of female mice against genital herpes. Nat Biotechnol 1996;14:468-71.

46 Lewicki J, Simpson D, Chang C, et al. Native vaginal lactobacilli engineered as a delivery vehicle for anti-HIV protein microbicides. Microbicides 2004, 2004: (abstract number, 02465)

47 Taha T. Safety, acceptability and efficacy of a penile microbicide wipe. Microbicides 2004. London, 2004: (abstract number, 02436).

48 Misegades L, Page-Shafer K, Halperin D, et al. Anal intercourse among young low-income women in California: an overlooked risk factor for HIV? AIDS 2001;15:534-5.

49 Alves K, Page-Shafer K, Caseiro M, et al. Risk factors for incident HIV infection among anonymous HIV testing site clients in Santos, Brazil: 19961999. J Acquir Immune Defic Syndr 2003;32:551-9.

50 Tsai CC, Emau $\mathrm{P}$, Jiang $Y$, et al. Cyanovirin- $\mathrm{N}$ gel as a topical microbicide prevents rectal transmission of SHIV89.6P in macaques. AIDS Res Hum Retroviruses 2003;19:535-41.

51 Tabet S, Surawicz C, Horton S, et al. Safety and toxicity of nonoxynol-9 gel as a rectal microbicide. Sex Transm Infect 1999;26:564-71.

52 World Health Organization. WHO/CONRAD technical consultation on nonoxynol-9, World Health Organization, Geneva, 9-10 October 2001: summary report. Reprod Health Matters 2002;10:175-81.
53 Shattock $\mathbf{R}$. The rationale for combination microbicides: viral and cellular targets. The Microbicide Quarterly 2003:1-5.

54 De Zoysa I, Elias CJ, Bentley ME. Ethical challenges in efficacy trials of vaginal microbicides for HIV prevention. Am J Public Health 1998;88:571-5.

55 Wu T. Considerations for clinical development of topical microbicides: a US regulatory perspective. Microbicides 2004. London, 2004.

56 Stein ZA, Myer L, Susser M. The design of prophylactic trials for HIV: the case of microbicides. Epidemiology 2003;14:80-3; discussion 83-4.

57 Padian N. Commentary: the design of prophylactic trials for HIV. Epidemiology 2003;14:83-4.

58 Van Damme L, Wright A, Depraetere K, et al. A phase I study of a novel potential intravaginal microbicide, PRO 2000, in healthy sexually inactive women. Sex Transm Infect 2000;76:126-30.

59 Dezzutti $C$, James $V$, Ramos A, et al. An in vitro comparison of topical microbicides for the prevention of HIV transmission. Microbicides 2004. London, 2004: (abstract number, 02600).

60 Moench T, Doncel GF, Cone RA. The HEC placebo: designed for "no effect". Microbicides 2004. London, 2004: (abstract number, 02609)

61 Fleming T, Richardson B. Some design issues in trials of microbicides for HIV prevention. J Infect Dis 2004;190:666-74.

62 Padian N. Evidence-based prevention: increasing the efficiency of HIV intervention trials. J Infect Dis 2004;190:663-5.

63 Pinkerton S. Sexual risk compensation and HIV/STD transmission: empirical evidence and theoretical considerations. Risk Anal 2001;21:727-36.

64 Steiner MJ, Feldblum PJ, Padian N. Invited commentary: condom effectiveness-will prostate-specific antigen shed new light on this perplexing problem? Am J Epidemiol 2003;157:298-300; discussion 301-2.

65 Macaluso M, Lawson ML, Hortin G, et al. Efficacy of the female condom as a barrier to semen during intercourse. Am J Epidemiol 2003;157:289-97.

66 Lawson ML, Macaluso M, Duerr A, et al. Partner characteristics, intensity of the intercourse, and semen exposure during use of the female condom. Am J Epidemiol 2003;157:282-8.

67 Walsh TL, Frezieres RG, Nelson AL, et al. Evaluation of prostate-specific antigen as a quantifiable indicator of condom failure in clinical trials. Contraception 1999;60:289-98.

68 Galvao L, Macaluso M, Oliveira L, et al. Effectiveness of the female and male condom in preventing exposure to semen during vaginal intercourse: a randomized trial. National HIV Prevention Conference. Atlanta, GA, 2003.

69 Foss AM, Vickerman PT, Heise L, et al. Shifts in condom use following microbicide introduction: should we be concerned? AIDS 2003;17:1227-37.

70 Posner S, van der Straten A, Kang M, et al. The effect of introducing the diaphragm on male condom use. Microbicides 2004. London, 2004: (abstract number, 02684)

71 Richens J, Imrie J, Copas A. Condoms and seat belts: the parallels and the lessons. Lancet 2000;355:1555-6.

72 Adams J, Hillman M. The risk compensation theory and bicycle helmets. Inj Prev 2001;7:89-93.

73 Martin JN, Roland ME, Neilands TB, et al. Use of postexposure prophylaxis against HIV infection following sexual exposure does not lead to increases in high-risk behavior. AIDS 2004; 18:787-92.

74 Park BJ, Stergachis A, Scholes D, Heidrich FE, Holmes KK, Stamm WE. Contraceptive methods and the risk of Chlamydia trachomatis infection in young women. Am J Epidemiol 1995;142:771-8.

75 Quinn R, O'Reilly K. Contraceptive practices of women attending the sexually transmitted disease clinic in Nashville, Tennessee. Sex Transm Dis 1985; 12:99-102.

76 McCormack WM, Rosner B, McComb DE, et al. Infection with Chlamydia trachomatis in female college students. Am J Epidemiol 1985;121:107-15.

77 Berger GS, Keith L, Moss W. Prevalence of gonorrhoea among women using various methods of contraception. Br J Vener Dis 1975;51:307-9.

78 Keith L, Berer GS, Moss W. Cervical gonorrhea in women using different methods of contraception. J Am Vener Dis Assoc 1976;3:17-19. 